\section{Does the end result justify the expense?}

The case is described of a 70-year-old man, recently retired but fit and independent, except for haemophilia from which he had suffered all his life. However, he then had rectal bleeding for which he required treatment in hospital. To counteract the bleeding tendency he was transfused with various blood products but none was successful, and finally after an operation to determine precisely the source of the rectal bleeding, he developed peritonitis and died. Apart from the cost of hospital inpatient treatment and the blood products available from blood banks, $£ 8500$ was spent on blood products bought in the USA.

This case is discussed by a professor of haematology, a director of a regional blood transfusion service, a medical defence specialist, a consultant in geriatric medicine, and finally by a member of a university department of moral philosophy.

All the medical commentators agree that a very large sum of money was spent in treating this patient, particularly in buying supplies of commercially produced factor VIII which also carries attendant medical risks. But while this is so, it is also argued that the doctors in charge of the case could have done no other as the fatal outcome could not have been foreseen and a doctor's duty is to treat his patient to the best of his ability, even though in this case the patient was elderly and in the hospital concerned other projects had to be cancelled.

The 'battle' of the treatment of the aged versus the young is touched upon by all the contributors but it is left to the moral philosopher to examine it more closely and incidentally to direct attention to the nature of the National Health Service which is neither a paternalistic system nor an insurance scheme (thought to be so by some to be a more palatable notion) but a welfare scheme in which the state forces its citizens to do things for the general good. For the moral philosopher age is irrelevant to the debate. Perhaps the consultant in geriatric medicine should have the last word: if the patient had been in the hands of a single general physician or geriatrician, he says, he would have been seen as a whole person and the arguments surrounding the case with hindsight would never have arisen.

\section{Case history}

A 70-year-old haemophiliac (factor VIII deficiency) was admitted to hospital with rectal bleeding and an iron-deficiency anaemia of $9 \mathrm{~g} / \mathrm{100} \mathrm{ml}$ haemcglobin. Haemophilia had been diagnosed at the age of 3 , and since then he had developed a number of haemarthroses, and had had two dental haemorrhages. He was not crippled, however, and was otherwise a fit man. He had recently retired. He lived on his own and was quite capable of looking after himself.

THE TREATMENT AND ITS COST

On admission, a barium enema revealed a colonic polyp which was presumed to be the source of the bleeding. It was decided to give him factor VIII to stop the bleeding, but on studying his coagulation situation it was discovered that he had an antibody, an inhibitor of factor VIII, which meant that very large amounts of replacement were needed. Initially he was given this in the form of cryoprecipitate, obtained from the National Transfusion Service, as well as whole blood to treat his anaemia. Attempts were made with steroids and cytotoxic drugs to suppress the antibody but these were unsuccessful. He continued to bleed, and the Lister Institute concentrate was also used. When supplies of these products from the local region were exhausted, he was given bovine factor VIII, to which he developed rigors, and porcine factor VIII, which gave him a severe anaphylactic reaction. The alternative to this situation was an American, commercially available, freeze-dried preparation of human factor VIII, and under the cover of this a colonoscopy was performed, and the bleeding polyp removed. After this operation he bled severely, and a second colonoscopy was performed and a second polyp removed. Both of these growths were benign on histology.

In spite of these two operations he continued to bleed and require transfusion. He was therefore prepared for laparotomy, at which the length of colon which had held the polyps was removed and an end-to-end anastomosis performed. Postoperatively the bleeding was controlled by more commercial factor VIII, but the anastomosis leaked. He developed faecal peritonitis, unresponsive to antibiotics, and he died.

On assessment of the case it was discovered that apart from the cost of his inpatient care and the blood products available from the blood banks, $£ 8500$ had been spent on commercially available blood products. As a result of this expenditure, other projects in the hospital had to be cancelled. 


\section{Discussion}

J DARNBOROUGH Regional director, Regional Transfusion and Immuno-haematology Centre, Cambridge

The treatment of any acute case, whether it be of a bleeding haemophiliac or anyone else, must always mean the fullest use of available resources, both of expertise and materials, and this would certainly seem to have been so here. There cannot be, therefore, any ethical criticism of the management.

The projects which had to be cancelled because $£ 8500$ had been spent on this case are not specified, but the diverting of funds from one budgetary heading to another more urgent one is surely not unknown; indeed, it is a continual process in any National Health Service unit. If there is any cause for criticism here, it is not ethical but perhaps of budgetary arrangements which had not allowed for the possibility of using commercial factor VIII although this was known to have been available since 1974 to recognized haemophilia centres (which presumably this hospital was) through a Department of Health contract with two firms.

The two largest hospitals in East Anglia with running costs of $£ 6 \mathrm{~m}$ and $£ 3 \mathrm{~m}$ each per annum have annual drugs allocations of approximately $f^{280} 000$ and $£_{128} 000$ respectively. For either of these, expenditure of this magnitude on a single patient would thus represent 3-6 per cent of their total annual drug allocation, or $0.14-0.28$ per cent of their total budget. Whilst one can probably justify such spending in a life-saving situation, the diverting of funds from other patients on such a scale for prophylaxis or cold surgery in haemophiliacs would be much more difficult to defend, either financially or ethically.

There is, however, a broader aspect to all this, should we use commercial human blood products at all? Both firms selling factor VIII concentrate are US firms, and the plasma used for these American manufactured factor VIII preparations is obtained from paid donors, some of it being imported into the USA from other countries. There are arguments for and against voluntary versus paid blood donors, all of which generally hinge round the motivation of donors and adequacy of supplies of blood and blood products. Titmuss (1970) provides strong and convincing arguments for the volunteer system such as exists in the UK; the Institute for Economic Affairs has argued the opposite case (1968 and 1973). It is one of the basic tenets of the transfusion services in Britain that the donor should be voluntary. Any system involving payment to donors would be morally unacceptable, not only to the transfusion services but to many of the donors also. The buying of human blood (or indeed any other human tissue) and the selling of that blood or products made from it by a commercial concern must introduce a profit motive and, as Titmuss points out in his book, bring the whole business $m$ into the sphere of the "law of the market place' which, as he shows, can eventually interfere witho the proper relationships between donor, physician and patient. He describes a case in the USA where? the organizers of a non-profit-making community? blood bank, which had been set up in opposition to a highly suspect commercial blood bank, were found? guilty of having been 'illegally joined together in尺 conspiracy to restrain commerce in whole humanes blood'.

Apart from the moral aspect, there are medical problems too with paid donors. For many years $\vec{\omega}$ they have been suspected of a higher hepatitiso carrier rate than voluntary donors. The discovery of the hepatitis $\mathrm{B}$ antigen ( $\mathrm{HB} \mathrm{Ag}$; Australiaantigen) and the mass testing of donors for HB Ag: has confirmed this and tremendously reinforced $\vec{D}_{\infty}$ the arguments for voluntary systems. American figures have shown that the incidence of $\mathrm{HB} A g$ in paid donors is Io times higher than in voluntary donors (Cherubin and Prince, 1971). As no HB AgD test is roo per cent reliable, any paid donors, eveno $\mathrm{HB}$ Ag negative, must therefore be regarded as a much greater hepatitis risk than voluntary donors. Alter, Holland, Purcell, Lauder, Jemstone, Morrow $\vec{c}$ and Schmidt (1972) have shown in a prospective of study that exclusion of $\mathrm{HB} \mathrm{Ag-positive} \mathrm{donors} \mathrm{can}$ achieve a 25 per cent reduction in post-transfusiono hepatitis, but the exclusion of paid donors would $s$ achieve a 70 per cent reduction. It was the discovery and introduction of $\mathrm{HB} \mathrm{Ag}$ testing as much as anything which led the Us Secretary of Health, Education and Welfare to announce in July $1973 \overrightarrow{\overrightarrow{0}}$ the establishment of a US National Blood Policy directed towards an all-voluntary supply of blood.

This risk of hepatitis has already been demonstrated. A high proportion of the British haemophiliacs] receiving commercial factor VIII concentrate have subsequently developed hepatitis.

It has been estimated that if commercial factor VIII was exclusively used for haemophiliacs in Britain, the total annual cost would be $£ 3 \mathrm{~m}-£ 4 \mathrm{~m}$ (MRC Blood Transfusion Research Committee Working Party, 1974). Home-produced materia from UK voluntary donors would cost roughly aboute. a quarter of this, with a considerably smaller ${ }_{0}$ hepatitis risk. There is no doubt that this could be done in the NHS by the transfusion services; the donors are available, as is the fractionation capacity. The Department of Health has accepted the recommendations of an Expert Committee on the Treatment of Haemophilia, which are basically怘 those suggested by the MRC Blood Transfusion Research Committee Working Party (1974), and recently special funds have been made available to the transfusion service to do this. It will, however be not until 1977 that an adequate rate of home production will be reached. In the meantime? therefore, we are in an ethical cleft stick in that 
blood products from donor sources which would not be acceptable here are being imported at high cost as, one hopes, a temporary expedient.

\section{References}

Alter, H J, Holland, P V, Purcell, R H, Lauder, J J, Jemstone, S M, Morrow, A G and Schmidt, P J (1972). Posttransfusion hepatitis after exclusion of commercial and hepatitis B antigen-positive donors. Annals of Internal Medicine, 77, 691.

Cherubin, E D, and Prince, A M (1971). Serum hepatitis. Specific antigen (SH) in commercial and volunteer sources of blood. Transfusion, II, 25-27.

Cooper, M H, and Culyer, A J (1968). The price of blood (Hobart Paper 4I). London: Institute of Economic Affairs.

Titmuss, $R M$ (1970). The gift relationship. London: George Allen \& Unwin Ltd.

The economics of charity (1973). London: Institute of Economic Affairs.

Report of the Medical Research Council's Blood Transfusion Research Committee Working Party on the Cryoprecipitate method of preparing AHF concentrates (1974). Factor VIII concentrates made in the United Kingdom and the treatment of haemophilia based on studies made during 1969-72. British fournal of Haematology, 27, 391-405.

G I C INGRAM Professor of Haematology, St. Thomas' Hospital, London

I have three technical comments on the management of the case, whose relevance will depend on the date (unspecified) on which the relevant decisions had to be taken, because this will have a bearing on the likelihood that the appropriate information would have been available to those concerned. First, one would like to know the initial level of the patient's anti-factor VIII antibody when treatment was begun to assess the reasonableness of the expectation that the problem could have been managed with cryoprecipitate at all; it might have used less antihaemophilic material in the end if commercial concentrate had been used at the beginning to neutralize the antibody and the less concentrated NHS materials used thereafter. Second, it might well have been appropriate in a patient of this age to try to control the bleeding first with a 'prothrombin concentrate' as suggested by Kurczynski and Penner (1974) (New England Fournal of Medicine, 1974, 291, 164) following the report of Fekete et al in 1972 (International Congress of Haematology, São Paulo, Brazil). This might have saved a great deal of the factor VIII which was required. Third, it is not clear whether the steroids and cytotoxic drugs were used to try to lower the level of the antibody which was found, or to suppress its reappearance after it had been initially neutralized with factor VIII; the first alternative would not seem to be reasonable, and exchange transfusion might have been more successful if lowering of the antibody titre was intended.

Assuming that the right decisions were taken in the light of information then and there available on the above matters, there remain the problems of, first, the use of expensive or scarce materials in the treatment of the elderly; second, the choice between the treatment of different patients when facilities do not allow the treatment of all; and third, the problems of withholding treatment. First, with human blood products generally, the attempt should always be made to relate their use to the prognosis of the case; other things being equal, one should have a higher threshold for ordering human blood products for the elderly than for younger patients. Second, in discussing the problems of insufficient treatment for all, so that one is forced to choose between treating one patient or another, the moral problem can only be clearly faced if the doctor has sufficient knowledge about all the alternative patients; it is not clear from the remark at the end of the last paragraph of the case report whether this problem clearly faced the doctors at the time of treating this patient, or whether the issue only became apparent retrospectively. Third, either or both of these issues may lead to the problems of deliberately withholding treatment. Relevant considerations in a haemophiliac would be the patient's degree of insight based on his knowledge of his disorder and his ability to interpret the actions of his attendants, his own wish to live, and, of course, the prognosis of the individual incident. In this particular case, it might have been possible to administer drugs to diminish the patients' awareness or to cloud his consciousness so that treatment could have been withheld without that becoming a cruel act.

\section{A L GWYNne The Medical Defence Union, London}

We are told of a 70-year-old man with a treatable congenital blood dyscrasia who was otherwise fit. He had recently retired, was not crippled by his disease, and although he lived alone, was able to look after himself. Subsequent events proved that he was not suffering from malignant disease. Given the patient's informed consent, the doctors under whose care he came in hospital had no alternative to treating him. Indeed, they had a definite legal, ethical and moral duty to treat him.

Once a patient is accepted by a hospital for treatment, a legal duty is owed to him by all concerned. He must be treated with appropriate care and skill and in accordance with contemporary teaching and practice. Parliament, in various Acts, has placed upon the Secretary of State for Social Services a duty to provide hospital accommodation and medical and other services required for the diagnosis and treatment of illness. It is the duty of 
every hospital authority to provide proper and sufficient drugs and medicines for supply to patients on the prescription of medical practitioners in the service. To put it another way, practitioners responsible for treating patients can with justification expect the hospital authority to provide all proper facilities for so doing. There is no mention in the legislation of cost. Medical practitioners have a common-law duty to their patients, breach of which invites a claim in negligence.

To return to the specific case, the responsible practitioners were obliged to continue to transfuse the patient. They had exercised clinical judgment in undertaking treatment and could only have stopped if that had been the patient's wish or if clinically it was not in his interests to proceed. They certainly could not have discontinued therapy because of cost.

The case exemplifies the problem of the individual's needs versus the finite resources of society. Other medical examples demonstrating the moral dilemma in the apportionment of resources arise in providing facilities for the treatment of mental disorder, renal disease, congenital abnormalities, such as spina bifida, and organ transplantation. The latter subject tends to generate more heat than light. The Chief Medical Officer has written on cardiac transplantation that, although clinical decisions about the treatment of individual patients are matters for the consultants concerned, diversion of resources from other hospital work is a matter for the hospital authority and, one might add, for society. Value judgments are raised concerning the relative worth of individuals and the needs of society. Are the costs of screening programmes justified by their beneficial results? Should we be investigating and treating infertility in a world where overpopulation and starvation are prominent features? Where there is need for selection, eg, which patients are to be dialysed, the practitioner may be brought into conflict with the traditional ethic of the preservation of life.

It is easy to pose questions, but there are no simple answers. Society (?Parliament) must decide on the allocation of resources: doctors can assist by providing facts and opinions. In daily practice the doctor is inevitably more concerned with patients than with such esoteric matters. Morally, ethically and legally, he must continue to exercise his best professional judgment in the interests of the patient of the moment.

\section{K DAvison Consultant Geriatric Physician, Ches- terton Hospital, Cambridge}

This case, in its bare essentials, poses the question, should the energetic and expensive treatment of an elderly haemophiliac have taken priority over other (unspecified) hospital activities? Assuming that these latter are of themselves commendablem and of benefit to the patients the reader might with hindsight regard the whole case as a lamentable squandering of valuable resources. Unfortunately $\Rightarrow$ clinical medicine has to be practised without $\mathrm{a}^{\mathrm{p}}$ detailed knowledge of what the future holds for each of our patients. Thus, many treatments are started which later prove to be ineffective if not downright deleterious. Indeed the simplest medica $\mathbb{R}$ or surgical treatment can on occasion have a fatafs outcome. To assess clinical management in this case it is necessary to present the choices sequentiallyas they presented clinically.

Let me start by a consideration of the patiens himself. The key information available is that he्ष was a fit, independent elderly man who had onlyrecently retired and who was quite capable of $\triangleright$ looking after himself and so he represented ano잉 eminently worthwhile life. He was entering the 'golden age' of retirement, apparently in good? physical health. He was not particularly old by $\vec{\square}$ current standards as a glance around the generalo medical wards of any of our district general hospitalsळ్ would show us. His main pathology (the haemo- $\frac{3}{0}$ philia) was essentially benign, and therefore his prognosis good. He had for more than 70 years $\vec{\varphi}$ coexisted peacefully with his haemophilia and there or was every reason to expect him to continue in this way. Without the haemophilia at the age of 70 ando being in good general health he could be expected to live for a further nine years on average. As judged $\bar{O}$ by his previous 'track record' the haemophilia was $\frac{\triangle}{\varnothing}$ unlikely to do a great deal to alter this expectation. The new development of rectal bleeding must have $\overrightarrow{\vec{O}}$ caused great alarm to the patient and to his medical 3 attendants. 'Is it a cancer?', they would ask themselves, and immediately set about trying to answer the question. Further investigation revealed the $\overline{3}$ second and relatively benign pathology, the colonic polyp. At this stage for the clinicians not to treat 3 the iron-deficiency anaemia, not to treat the

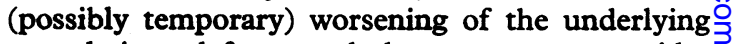
coagulation defect, and later not to consider surgical treatment for the polyp would have been ${ }^{\circ}$ unthinkable. Certainly not to treat in the setting $>$ of a district general hospital in Britain would be unthinkable in a society which accepts as common- $N$ place organ transplantation, salvage surgery on very seriously injured victims of violence, and the medical $N$ treatment of many patients, suffering say from $\omega$ some of the leukaemias, for which the prognosis is very poor, and indeed more severe haemophiliacs at younger ages.

Beyond this point, however, the situation in the $\stackrel{?}{?}^{?}$ case under discussion develops into a cascade of $\frac{T}{T}$ calamities and final disaster. As the disaster unfolds $\frac{0}{\mathbb{D}}$ it is possible to question the activities and the $\frac{\mathbb{Q}}{\mathbb{P}}$ motivations of the doctors concerned, not because $\triangle$ they started treating the man, but because they went 2 on treating him in the face of obvious failure to doo 
good. In my opinion the treatment of the patient, although correctly begun, could perhaps have been interrupted at one of a number of points.

I) When all 'normal' supplies of supporting cryoprecipitate ran out, that is, before the decision to use commercial material: this option may have been rejected on the grounds that interventional action (colonoscopy) was planned, and this could well have been curative.

2) Major surgery in a haemophiliac, in this case laparotomy, especially one in this already difficult situation, is always a potentially hazardous undertaking. However, it is easy to sympathize with the patient's attendants, looking for success and possibly uneasily aware that the sum of all their efforts was actually a worsened haemorrhagic situation. (Or perhaps like Macbeth they may simply have felt 'in blood stepped in so far that ... returning were as tedious as go o'er' Act III, scene 4.)

3) At the onset of peritonitis: a postoperative death with its inevitable suggestion of failure of surgical technique is almost harder for a surgeon than for the patient to bear! However, by this stage bleeding had stopped, and to have withheld antibiotics at this point would scarcely have been consistent with the previous active endeavour.

It is apparent from this sequence that 'cost effectiveness' as a concept can hardly have affected the progress of this case until very late in the day. Perhaps when, and if, it did it might have been easier to call a halt to the proceedings, say at point I or 2 , had the patient been under the care of a single general physician or geriatrician, rather than a series of specialists as appears here (haematologist, endoscopist, surgeon), each a little way removed from complete responsibility and decision making. In general decisions as complex as valuing life, to its owner and to those in a caring or dependent relationship to him, rarely benefit from discussion in committee, particularly where speed is of the essence.

In the present-day political and economic climate decisions of value concerning human life will increasingly force themselves into attention, but no degree of predetermined administrative or multidisciplinary consensus will ever do much to ease a problem such as the one discussed here - a rapidly changing clinical picture, with different personnel and differing levels of responsibility by day and night - a routine situation going wrong, and little time (or inclination) to sit back calmly and objectively in order to give a wisely considered 'thumbs-down'.

As a final comment, may I say that, leaving aside the particular detail relating to this case, the whole question of the use of increasingly scarce resources on behalf of an increasingly aged and hence (economically) unproductive population is one that nags the mind of many doctors, and yet it is so difficult to put a value on life just by introducing the parameter of age unless one is dealing with the very extreme of old age. How, for example, does one balance the needs of a 25-year-old patient with end-stage renal failure in need of a new kidney, the previous transplant having been rejected, against those of a spry 80-year-old with a chest infection in need of an antibiotic so that he can go back to his active retirement. These of course are extremes meant to illustrate that age of itself is a very poor criterion on which to make value judgments, yet inevitably to some degree it must come into the equation. Certainly running away from problems such as these does not make the clinical decisions any easier. Surely the time is ripe for active discussion of medical ethics to be an integral part of any medical training programme. At the present time these complex and important value judgments are dictated partly by general medical training, partly by specialty training and interests, and partly by social insight or prejudices and little or not at all by the influence of a body of evolved medical ethics.

\section{ELIZABETH TELFER Department of Moral Philosophy, University of Glasgow}

In a case like this, as one of the other contributors points out, the appropriateness of the decisions taken depends very much on what knowledge was available and on what exactly was being sacrificed for the sake of this patient. But there are two broader issues raised by the case on which a philosophical comment may be made which does not depend on such details.

The first issue concerns the value to be set on the life of the elderly. There is a tendency to feel that, if a choice must be made because of scarce resources, the life of a young person, other things being equal, should be saved in preference to that of an old one. It is beside the point to object that all life is sacred if the situation is such that someone's life must be sacrificed in any case. But it is difficult to find grounds for sacrificing the elderly which furnish more than a presumption against them, often rebuttable in a particular case. For example, the elderly may be said to be less useful to society, less personally valued or less capable of an enjoyable life than the young. But there are many obvious exceptions to these very crude generalizations.

There are, however, two points in favour of sacrificing the elderly which are perhaps less easily rebutted. The first is that treatment of the elderly is less likely to be fully effective, so that even where their lives before they became ill possessed to the full those features - usefulness, enjoyment, value to others - which might lead one to give them preference, the chance of restoring them to the full quality of that life may be slight. The second point is of course that an older person's expectation of life is shorter, so by saving a young person's life the 
doctor has probably saved a life with a longer extent. By this argument a doctor would be justified in saving an old person rather than a young one where the young person's expectation of life was for some reason exceptionally short; and this seems acceptable.

But there are two consequences of the 'expectation of life' argument which are perhaps less acceptable. First, it emphasizes sheer quantity (extent in time) of life rather than quality, though the doctor might well retort that the respective quality of two lives is not something he can be expected to judge. Secondly, it carries the consequence that a young baby's life is in general to be preferred to that of an old person. Is this obviously right, or might it be said that a young baby does not yet possess the self-consciousness which is essential to fully human life?

The second issue raised by this case is the very nature of the National Health Service. The National Health Service is described as a state health insurance scheme; but two features of this case show how different the scheme is from the normal idea of an insurance policy. In ordinary insurance, a higher risk carries a higher premium; but the haemophiliac, so far from paying a higher premium, probably pays a rather lower one than the average person, in that his insurance contributions will be less regular. Again, insurance in general involves an upper limit on the amount which can be claimed; but in this case no limit was set on the sum which might be spent in an effort to save the sufferer's life. (There can be discussion of whether too much was spent, but not in terms of a maximum claim.)

The truth is that the National Health Service is not really an insurance scheme at all, though it was originally presented as such to make it more palatable to some opponents. It is a welfare scheme, exemplifying the principle, 'from each according to his means, to each according to his need'; and at haemophiliac's means may be very small if he is:. often unfit to work, his need very great. Seen in? this way, the NHS seems less obviously open to the common charge that it is paternalistic. For paternal of ism is the process of urging or compelling someone to do something for his own good, or what the urges or compeller conceives to be such, whereas thes National Health Service, or so I have suggested $\stackrel{\mathbb{\Omega}}{\Omega}$ compels people to do things for the general good. In this respect too the National Health Service differsfrom the normal case of insurance, for the point of insurance normally is to benefit the insurer himsel $\hat{\epsilon}_{\omega}$ or his immediate circle.

But there are objections to the principle of the National Health Service other than that of paternal ism. Why, it might be asked, should people be forced to help each other in this way? An answerbo might be suggested in terms of the State's mora $N$ function. Because it is wrong to kill people, the State punishes people who do this; similarly, because it is right to help those in need, the State makesp people do this. In other words, the State has the function of enforcing our most important dutie 8 (and of setting up systems whereby we can carrye them out effectively).

There are many objections to this argument of Perhaps the chief one is that those in need, in this case, do not require State defence; they can look after themselves by insurance schemes in the trues sense of the term. Defenders of the Nationap Health Service might point out that there will alo ways be those, like our haemophiliac, who are too bad a risk to be taken on by a commercial scheme $\overrightarrow{\vec{D}}$ and maintain that a partial National Health Service consisting only of bad risks, would not be viable But more fundamentally they will argue that there. is more moral value in a system of mutual aid, every if imposed, than in one of self help. 